\title{
The Optimization and Mathematical Modeling of Quality Attributes of Parboiled Rice Using a Response Surface Method
}

\author{
Khurram Yousaf, ${ }^{1}$ Chen Kunjie, ${ }^{1}$ Chen Cairong, ${ }^{1}$ Adnan Abbas, ${ }^{2}$ Yuping Huang, ${ }^{1,3}$ \\ Chaudhry Arslan, ${ }^{4}$ and Zhang Xuejin ${ }^{5}$ \\ ${ }^{1}$ College of Engineering, Nanjing Agricultural University, Nanjing, Jiangsu 210031, China \\ ${ }^{2}$ College of Engineering, China Agricultural University, Beijing 100083, China \\ ${ }^{3}$ Biosystems and Agricultural Engineering, Michigan State University, East Lansing, MI 48824, USA \\ ${ }^{4}$ Department of Structure and Environmental Engineering, University of Agriculture, Faisalabad, Pakistan \\ ${ }^{5}$ Nanjing Research Institute for Agricultural Mechanization, Ministry of Agriculture, Nanjing 210014, China
}

Correspondence should be addressed to Chen Kunjie; kunjiechen@njau.edu.cn

Received 22 June 2017; Revised 4 September 2017; Accepted 19 September 2017; Published 20 November 2017

Academic Editor: Egidio De Benedetto

Copyright (C) 2017 Khurram Yousaf et al. This is an open access article distributed under the Creative Commons Attribution License, which permits unrestricted use, distribution, and reproduction in any medium, provided the original work is properly cited.

\begin{abstract}
The response surface methodology was used to optimize the hydrothermal processing conditions based on the rice quality parameters of the Rong Youhua Zhan rice variety (Indica). The effect of soaking temperature $\left(29.77,40,55,70\right.$, and $80.23^{\circ} \mathrm{C}$ ), soaking time $(67.55,90,120,150$, and $170.45 \mathrm{~min})$, and steaming time $(1.59,5,10,15$, and $18.41 \mathrm{~min})$, each tested at five levels, on percentage of head rice yield (HRY), hardness, cooking time, lightness, and color were determined, with $R^{2}$ values of $0.96,0.94$, $0.90,0.88$, and 0.94 , respectively. HRY, hardness, cooking time, and color increased with process severity while lightness decreased, although HRY decreased after reaching a maximum. The predicted optimum soaking temperature, soaking time, and steaming time were $69.88^{\circ} \mathrm{C}, 150 \mathrm{~min}$, and $6.73 \mathrm{~min}$, respectively, and the predicted HRY, hardness, cooking time, lightness, and color under these conditions were $73.43 \%, 29.95 \mathrm{~N}, 32.14 \mathrm{~min}, 83.03 \mathrm{~min}$, and $12.24 \mathrm{~min}$, respectively, with a composite desirability of 0.9658 . The parboiling industry could use the findings of the current study to obtain the desired quality of parboiled rice. This manuscript will be helpful for researchers working on commercializing parboiled rice processes in China as well as in other countries.
\end{abstract}

\section{Introduction}

Rice is a staple food consumed by more than half of the world's population. The world's annual production of rice in 2014 was estimated at 744.4 million tons. The Asian continent plays a vital role in rice production, with rice production in this region recorded as 673.6 million tons in 2014, accounting for $90 \%$ of the world's overall rice paddy production. Researchers are working to find the most efficient way to process rice to preserve its nutritional value and to determine the best germination conditions. In general, parboiling is a hydrothermal process used on rough rice and includes various treatments to improve rice quality. Parboiling consists of a series of processing stages including the soaking, steaming, and drying of paddy rice grains. The parboiling process has resulted in increased milling yield and enhanced nutritional value and resistance to spoilage $[1,2]$.
The major advantages of the parboiling method include rice starch gelatinization and hardening of the rice kernels, which reduces endosperm germination and breakage losses during milling [3]. Researchers have used a variety of techniques to parboil rice. Unnikrishnan and Bhattacharya [4] described pressure parboiling as low moisture parboiling in which the rice paddy is partially soaked or simply washed with water and then steamed at high pressure to gelatinize the rice starch. Walter et al. [5] used conventional and laboratory steaming methods in which rough rice was placed at $1.5 \mathrm{~kg} / \mathrm{cm}^{2}$ for 25 minutes, or, in the laboratory method, rough rice was steamed at ambient pressure for 20 minutes using an autoclave. The effectiveness of the steaming process depends on the steam conditions (either saturated in an open system or superheated in a closed system), steam pressure, and steaming time $[6,7]$. Another study revealed that, during the parboiling process, the steaming time has an influence on 
the physical characteristics of both the Japonica and Indica rice varieties. Moreover, steaming at $1 \mathrm{~kg} / \mathrm{cm}^{2}$ pressure for 15-30 minutes and steaming at atmospheric pressure for 12 minutes improved the cooking qualities, milling qualities, and physical characteristics [8]. The HRY should be increased after successful parboiling [9]. Bello et al. [10] reported that as steaming time was increased $45-75 \mathrm{~min}$, the hardness of individual rice kernels was found to increase from 13.1 to 25.3 $\mathrm{N}$. Islam et al. [11] revealed that average hardness increased with increasing steaming time $\left(60 \mathrm{~min}\right.$ at $90^{\circ} \mathrm{C}$ and $10 \mathrm{~min}$ at $100^{\circ} \mathrm{C}$ ). The effect of the parboiling process on the color value has been reported by many researchers $[1,12,13]$. The color value usually increases during parboiling while lightness decreases; the magnitude of the decrease in lightness increases with the severity of the parboiling process [14].

The response surface method (RSM) is an excellent approach used by many researchers to optimize the various factors in their research studies. Sharma et al. [15] reviewed the combined effects of various components on biomass growth using RSM. Response surface method is a unique combination of mathematical and statistical approaches to evaluate the optimal conditions by reducing the number of experiments between factors and responses [16]. Taghinezhad and Brenner [17] optimized the effect of two independent variables (soaking temperature and steaming time) on the quality characteristics of parboiled rice. Danbaba et al. [18] used RSM to optimize parboiling conditions (soaking temperature, steaming time, and drying time) to maximize HRY.

The scope of the study covers the optimization and mathematical modeling of rice quality properties during parboiling process by considering three independent variables (soaking temperature, soaking time, and steaming time). To the best of our knowledge, no optimization study has focused on predicting the combined effect of three factors (soaking temperature, soaking time, and steaming time on HRY, hardness, cooking time, lightness, and color) during parboiling process. Therefore, the current study was conducted to fill this research gap. This study was carried out to investigate (1) the optimum condition for rice quality parameters affected by process indicators (soaking temperature, soaking time, and steaming time) during parboiling process; (2) the prediction of parboiled rice quality indicators by mathematical modeling affected by three independent variables.

\section{Materials and Methods}

This study used a popular local Indica rice variety in China, Rong Youhua Zhan (RYZ), with an amylose content of $20.4 \%$ and an initial moisture content of $13 \pm 1 \%$ w.b. The RYZ rice was collected from the Rice Research Institute of Guangdong Academy of Agricultural Sciences, China. After proper cleaning and shade drying at safe moisture content, paddies were packed in $1 \mathrm{~kg}$ zip lock polyethylene bags and stored at $5 \pm 1^{\circ} \mathrm{C}$ in a refrigerator (BCD-232TDek, Hisense, China) for further experimentation [19].

2.1. Parboiling Process and Brown Rice Preparation. Hot soaking was done using an electronically controlled water bath
(DK-600A, China), adding $200 \mathrm{~g}$ of rice sample to $1000 \mathrm{ml}$ of deionized water, for a rice to water ratio of 1:5. The samples were soaked according to the five levels presented in Table 1, with stirring at 10-minute intervals. Extra water was discarded, the samples were tempered for $30 \mathrm{~min}$, and the open ends of the beakers were covered to prevent rapid cooling.

The soaked samples were treated at a working pressure of $1 \mathrm{~kg} / \mathrm{cm}^{2}\left(121^{\circ} \mathrm{C}\right)$ for different durations as shown in Table 1 using an autoclave (LS-35HD, China). After steaming, the pressure was released and the rice was tempered for 20-30 min [20]. The moisture content of the Indica samples was found to be within the range of $20.34-32.11 \%$. However, to avoid excessive fissuring, the rice samples were shade dried at room temperature $\left(25-30^{\circ} \mathrm{C}, 60 \pm 5 \% \mathrm{RH}\right)$ for 2 to 3 days to reduce the moisture content to $13 \pm 1 \%[21,22]$. The moisture content of the rice samples was measured by an oven drying method at $105 \pm 1^{\circ} \mathrm{C}$ for $24 \mathrm{~h}$ (w.b.). After that, the samples were coded according to the treatment applied and stored for moisture content equilibration and hardness stabilization.

2.2. Head Rice Yield. To measure percentage HRY, each $200 \mathrm{~g}$ sample of the whole paddy was dehusked using the laboratory satake rubber roller type rice husker (THU35C, China). The rice was polished with an abrasive type polisher for 90 seconds using satake CBS300AS, Japan [23]. Prior to HRY measurement, the broken grains were separated from the whole paddy and cleaned. The HRY was measured thrice and expressed as a percentage of the whole grains with respect to the paddy [10].

2.3. Hardness. The hardness was measured in terms of bending force. Hardness was measured by the three-point breakage mechanism using TMS-Pro texture analyzer, USA. The load of $500 \mathrm{~N}$ was applied to each grain at the 5\% accuracy level to measure the force $(\mathrm{N})$ using the texture lab procomputer program. As shown in Figure 1, the rice kernels were placed horizontally on the base plate with a clearance of $3.0 \mathrm{~mm}$ and a flat loading head of $1.0 \mathrm{~mm}$ thickness was used with a deformation rate of $0.5 \mathrm{~mm} / \mathrm{s}$. Fifty healthy whole grains were randomly selected for hardness testing from each sample, and the average values were reported as the final hardness [2].

2.4. Cooking Time. The cooking time was determined by the method proposed by Juliano [24]. Ten grams of whole kernels was weighed using an electronic balance (JM-A20002, China), mixed with deionized water, and then cooked for 20 minutes in vigorously preheated boiling water. Afterwards, ten rice kernels were randomly selected and pressed between two glass plates to identify translucent kernels. Samples were taken after every two-minute interval. This procedure was repeated until $90 \%$ of the whole kernels were found to be translucent, and this time was recorded as the cooking time [25].

2.5. Lightness and Color Measurement. The precision color reader (HP-200, China) was used for the color measurement. The instrument was first calibrated with white and black plates provided by the manufacturer. The results were 
TABLE 1: Design of CCD for independent variables.

\begin{tabular}{|c|c|c|c|c|c|c|}
\hline \multirow{2}{*}{ Run } & \multicolumn{3}{|c|}{ Coded form of factors } & \multicolumn{3}{|c|}{ Actual form of factors } \\
\hline & $X_{1}$ & $X_{2}$ & $X_{3}$ & $X_{1}\left({ }^{\circ} \mathrm{C}\right)$ & $X_{2}(\min )$ & $X_{3}(\min )$ \\
\hline 1 & -1 & -1 & -1 & 40 & 90 & 5 \\
\hline 2 & 1 & -1 & -1 & 70 & 90 & 5 \\
\hline 3 & -1 & 1 & -1 & 40 & 150 & 5 \\
\hline 4 & 1 & 1 & -1 & 70 & 150 & 5 \\
\hline 5 & -1 & -1 & 1 & 40 & 90 & 15 \\
\hline 6 & 1 & -1 & 1 & 70 & 90 & 15 \\
\hline 7 & -1 & 1 & 1 & 40 & 150 & 15 \\
\hline 8 & 1 & 1 & 1 & 70 & 150 & 15 \\
\hline 9 & -1.68 & 0 & 0 & 29.77 & 120 & 10 \\
\hline 10 & 1.68 & 0 & 0 & 80.23 & 120 & 10 \\
\hline 11 & 0 & -1.68 & 0 & 55 & 69.55 & 10 \\
\hline 12 & 0 & 1.68 & 0 & 55 & 170.45 & 10 \\
\hline 13 & 0 & 0 & -1.68 & 55 & 120 & 1.59 \\
\hline 14 & 0 & 0 & 1.68 & 55 & 120 & 18.41 \\
\hline 15 & 0 & 0 & 0 & 55 & 120 & 10 \\
\hline 16 & 0 & 0 & 0 & 55 & 120 & 10 \\
\hline 17 & 0 & 0 & 0 & 55 & 120 & 10 \\
\hline 18 & 0 & 0 & 0 & 55 & 120 & 10 \\
\hline 19 & 0 & 0 & 0 & 55 & 120 & 10 \\
\hline 20 & 0 & 0 & 0 & 55 & 120 & 10 \\
\hline
\end{tabular}

Note. $X_{1}=$ soaking temperature; $X_{2}=$ soaking time; $X_{3}=$ steaming time.

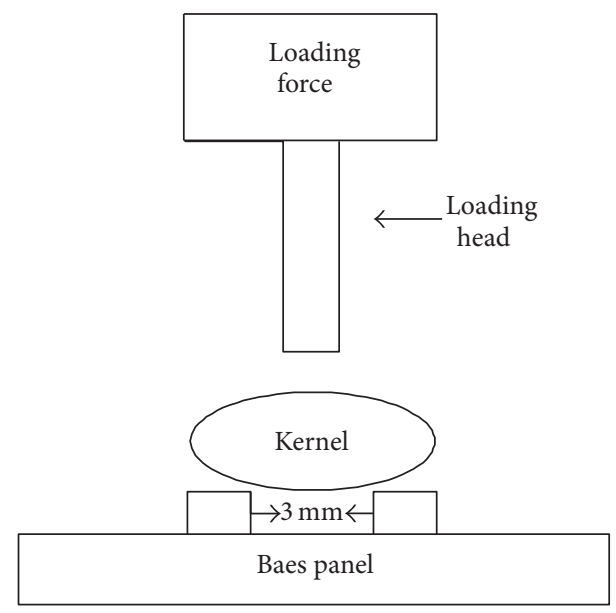

FIGURE 1: Schematic diagram of three-point bending deformation of rice kernel.

expressed in terms of $L^{*}, a^{*}$, and $b^{*}$ values, where the $L^{*}$ value represents brightness from black to white, a positive " $a$ " value represents redness while a negative " $a$ " value represents greenness, and a positive " $b$ " " value represents yellowness while a negative " $b$ " " value represents blueness. Six measurements were performed on each sample by shaking the sample gently to avoid error during the measurement, and average values were determined for further analysis. The color value $(B)$ of parboiled rice was determined using the following $[11,12,26]$ :

$$
B=\sqrt{a^{* 2}+b^{* 2}} .
$$

2.6. Experimental Design. RSM combined with central composite design (CCD) was used to investigate the effect of three factors on the response surface in the area of study. A CCD with three factors at five levels was investigated [27, 28]. The factors were selected based on reports in the literature that the factors with the maximum effect on HRY are soaking temperature, soaking time, and steaming time [17]. In the current study with the three independent variables of soaking temperature, soaking time, and steaming time, a total of 20 experiments were required, calculated as $2^{k}+2 k+6$, where $k$ is the total number of factors.

The responses could then be related to the factors by linear or quadratic models, enabling optimization. A quadratic model that also includes a linear model is shown in the following [28]:

$$
y=\beta o+\sum_{i=1}^{k} \beta_{i} X_{i}+\sum_{i=1}^{k} \beta_{i i} X_{i}^{2}+\sum_{i=1}^{k} \sum_{i=1}^{k} \beta_{i j} X_{i} X_{j}
$$

The CCD was executed using the statistical software DesignExpert $^{\circledR}$ 8.0.6 (Stat-Ease, Inc., USA). The fourteen experiments were investigated with a combination of six replicates to estimate the pure error. The run numbers and experimental 
conditions arranged by CCD with coded and actual values are shown in Table 1. The Design-Expert program was used to process the data using (2), and analysis of variance (ANOVA) was used to find the interactions between independent variables and responses. The fitness of the model was expressed by the coefficient of determination $R^{2}$, and its significance was also determined by an $F$-test.

\section{Results and Discussion}

3.1. CCD and Model Development. The process of paddy parboiling consists of three major steps, soaking, steaming, and drying of rough rice before milling. The benefits of the parboiling process are generally to obtain maximum HRY, increase nutritional value, and achieve resistance to spoilage by insects. Drying is a major factor in the paddy parboiling process, but the current study focused on the three factors of soaking temperature, soaking time, and steaming time. These three factors were chosen as independent variables, and their effects on the responses of HRY, hardness, cooking time, lightness, and color were determined. The actual responses and predicted values of each run are shown in Table 2.

The regression equations in coded form with the correlation coefficient $R^{2}$, adjusted $R^{2}$, and each coefficient of (2) are presented in Table 3. In the current study, a quadratic model suitably described the responses, and the $R^{2}$ values were acceptable. However, the hardness, cooking time, and color were positively affected by steaming time while lightness was negatively affected, all of which were highly significant at $(P<0.01)$, but steaming time did not affect the HRY. The soaking temperature and time mainly exerted significant effects $(P<0.01)$ on HRY, hardness, and cooking time, with no effects on lightness and color. Examining the interactions between factors, the interactions of soaking temperature with steaming time and with soaking-steaming time negatively affected the HRY and positively affected lightness. Furthermore, lightness was positively affected by the soaking temperature-time combination, and no other significant interaction effects were observed.

3.2. Head Rice Yield. The maximum HRY of $73.88 \%$ was obtained on run four when the soaking temperature, soaking time, and steaming time were $70^{\circ} \mathrm{C}, 150 \mathrm{~min}$, and $5 \mathrm{~min}$, respectively, and the minimum HRY of $60.82 \%$ was attained on the first run when these factors were $40^{\circ} \mathrm{C}, 90 \mathrm{~min}$, and $5 \mathrm{~min}$, respectively, as shown in Table 2 . Software analysis showed that the optimized values for soaking temperature, soaking time, and steaming time were $69.88^{\circ} \mathrm{C}, 150 \mathrm{~min}$, and $6.73 \mathrm{~min}$, respectively, resulting in a predicted HRY of $73.43 \%$. The RSM generated regression equation for HRY\% is presented in Table 3.

HRY\% was obtained as a function of soaking temperature $\left({ }^{\circ} \mathrm{C}\right)$, soaking time $(\mathrm{min})$, and steaming time (min) (Table 3$)$. Furthermore, the significance of the developed quadratic equation was cross-checked by an $F$-test. The analysis of variance (ANOVA) for the quadratic model indicated that model was significant (prob $>$ F 0.0001 less than $F$-value 29.22). The goodness of fit was evaluated by the coefficient of determination $R^{2}$, which ranges from 0 to 1 and should be more than $80 \%$ for a well-fitted regression model [29]. For HRY, $R^{2}$ and adjusted $R^{2}$ are 0.96 and 0.93 , indicating the appropriateness of the modeled regression equation for HRY if these variables are combined [17]. The nonsignificant lack of fit indicates that the model provides a good fit; the lack of fit $F$-value was 0.56 for HRY. Moreover, the current model was appropriate to capture the design space.

The response surface curves for HRY obtained from Design-Expert software are shown in Figure 2. The interactions among three independent variables were studied to maximize the percentage HRY. Figure 2(a) shows the $3 \mathrm{D}$ representation of the interaction between soaking temperature and soaking time. HRY was significantly improved by increasing soaking temperature and soaking time while the steaming time was at its center point.

The effect of soaking temperature and steaming time is depicted in Figure 2(b). The following interaction showed that, initially, HRY increased with increasing soaking temperature and steaming time up to a certain point; after this point, HRY decreased with gradually increasing steaming time, as previously expected. The experimental results for HRY in the current study were in agreement with [22].

The steaming time is the most important factor in the parboiling process. The percentage HRY was found to be minimal at the lowest soaking-steaming time combination $(60.82 \%)$ as shown in Figure 2(c). As soaking time increased, HRY also increased up to a particular steaming time, after which HRY was observed to decrease with a further increase in steaming time. This result was expected because long steaming time has been reported to reduce HRY [6]. In addition, at longer steaming times, rice grains absorbed excessive water, and husks were also observed to split. Furthermore, the parboiling process, in particular the steaming time, would also affect the gelatinization of starch. If the degree of gelatinization is high, then deformed grains would be obtained during parboiling, and deformed grains would be lost along with the exuded part of the endosperm $[11,30]$. According to Marshall et al. [31], it is not recommended to parboil paddies for a longer steaming period to increase the HRY. Similar results were found in the current study, with a maximum HRY (73.88\%) obtained at a lower steaming time (5 $\mathrm{min})$.

3.3. Hardness. Hardness is one of the most important rice quality characteristics during the parboiling process because milling breakage decreases with increasing hardness. The rice obtained by the parboiling process is harder than unprocessed rice [32]. Figures 3(a), 3(b), and 3(c) depict the relationships between hardness and process variables. Hardness increased with the severity of the parboiling process [33]. Figure 3(a) shows a linear relationship between hardness and the soaking temperature-time combination. Figures 3(b) and 3(c) shows that the hardness of parboiled rice increased with increasing steaming time, as the moisture absorbed by the rice grains during steaming causes starch melting and a decrease in $\Delta H$ at longer steaming durations [34]. In addition, increased severity of parboiling increases starch gelatinization, leading to low-quality rice [35]. The bending force ranged from 25.24 to $32.62 \mathrm{~N}$, comparable to the findings described by $[2,10]$. The RSM determined the 
TABLE 2: Observed and predicted values for HRY, hardness, cooking time, lightness, and color of rice.

\begin{tabular}{|c|c|c|c|c|c|c|c|c|c|c|}
\hline \multirow{2}{*}{ Run } & \multicolumn{2}{|c|}{ HRY (\%) } & \multicolumn{2}{|c|}{ Hardness (N) } & \multicolumn{2}{|c|}{ Cooking time (min) } & \multicolumn{2}{|c|}{ Lightness } & \multicolumn{2}{|c|}{ Color ( $b$-value) } \\
\hline & Observed & Predicted & Observed & Predicted & Observed & Predicted & Observed & Predicted & Observed & Predicted \\
\hline 1 & 60.82 & 59.85 & 24.56 & 25.24 & 23.0 & 24.6 & 86.5 & 85.5 & 11.80 & 11.88 \\
\hline 2 & 68.65 & 68.77 & 27.80 & 27.43 & 30.5 & 29.3 & 83.2 & 83.2 & 12.25 & 12.15 \\
\hline 3 & 65.57 & 65.59 & 28.46 & 28.01 & 30.0 & 27.4 & 83.2 & 82.5 & 12.02 & 11.59 \\
\hline 4 & 73.88 & 73.09 & 29.10 & 28.61 & 31.0 & 32.1 & 83.7 & 83.0 & 11.54 & 11.56 \\
\hline 5 & 65.31 & 65.98 & 30.02 & 30.82 & 28.0 & 27.3 & 78.6 & 78.1 & 13.93 & 13.94 \\
\hline 6 & 67.28 & 67.14 & 31.95 & 32.70 & 31.5 & 32.1 & 79.5 & 78.8 & 13.82 & 14.28 \\
\hline 7 & 66.96 & 66.72 & 31.65 & 32.33 & 29.5 & 30.1 & 80.3 & 79.0 & 14.02 & 14.15 \\
\hline 8 & 65.61 & 66.46 & 33.00 & 32.62 & 35.0 & 34.9 & 82.7 & 82.4 & 14.23 & 14.18 \\
\hline 9 & 63.35 & 63.60 & 30.24 & 29.37 & 24.0 & 25.7 & 80.1 & 81.1 & 13.30 & 13.44 \\
\hline 10 & 70.97 & 70.89 & 31.02 & 31.46 & 33.0 & 33.7 & 82.2 & 82.1 & 13.88 & 13.70 \\
\hline 11 & 68.21 & 68.34 & 30.36 & 29.40 & 28.5 & 27.4 & 81.5 & 81.3 & 13.56 & 13.30 \\
\hline 12 & 72.56 & 72.60 & 31.12 & 31.65 & 32.5 & 32.1 & 81.5 & 81.8 & 12.76 & 12.97 \\
\hline 13 & 62.34 & 63.24 & 24.02 & 24.54 & 27.5 & 27.4 & 84.3 & 84.9 & 10.03 & 10.30 \\
\hline 14 & 63.54 & 62.81 & 33.56 & 32.61 & 33.0 & 32.0 & 77.2 & 78.2 & 14.56 & 14.24 \\
\hline 15 & 69.69 & 70.41 & 31.25 & 31.79 & 28.5 & 29.7 & 80.9 & 81.6 & 13.45 & 13.43 \\
\hline 16 & 70.21 & 70.41 & 32.85 & 31.79 & 29.0 & 29.7 & 81.8 & 81.6 & 13.58 & 13.43 \\
\hline 17 & 69.43 & 70.41 & 31.90 & 31.79 & 30.0 & 29.7 & 81.7 & 81.6 & 12.94 & 13.43 \\
\hline 18 & 71.66 & 70.41 & 31.40 & 31.79 & 29.5 & 29.7 & 80.9 & 81.6 & 13.45 & 13.43 \\
\hline 19 & 71.65 & 70.41 & 31.65 & 31.79 & 31.0 & 29.7 & 81.4 & 81.6 & 13.89 & 13.43 \\
\hline 20 & 69.87 & 70.41 & 31.63 & 31.79 & 29.5 & 29.7 & 80.4 & 81.6 & 13.24 & 13.43 \\
\hline
\end{tabular}

regression equation for hardness in coded units shown in Table 3.

3.4. Cooking Time. The relationship between cooking time and the independent variables was captured in a quadratic model $\left(R^{2}=0.90\right.$ and adjusted $\left.R^{2}=0.82\right)$. The cooking time was influenced by all three factors, but soaking temperature and soaking time had significant effects while the effect of steaming time was not significant. The maximum $(35 \mathrm{~min})$ cooking time was observed for run eight (Table 2), with the minimum (23 min) observed for the first run. Figure 4(a) depicts the soaking time and soaking temperature interaction, showing that decreasing these two factors reduced the cooking time of parboiled rice. The relationship between cooking time and the independent variables is presented in Table 3.

3.5. Lightness. Lightness is an important quality indicator for the rice parboiling process; market value is directly related to lightness as consumers dislike dark colored rice [36]. The effects of soaking temperature-time and steaming time are shown in Figure 5. Lightness decreased as the severity of the parboiling process increased. The steaming duration had a significant effect on the lightness of parboiled rice as shown in Figures 5(b) and 5(c); the combination of soaking time-temperature and steaming time reduced the lightness values. The darkest value (77.2) was observed for run fourteen (Table 2) when soaking and steaming times were 120 and
$18.41 \mathrm{~min}$, respectively. The maximum brightness (85.5) was observed at the lowest parboiling condition when the soaking temperature-time and steaming time were $40^{\circ} \mathrm{C}, 90 \mathrm{~min}$, and $5 \mathrm{~min}$, respectively. The regression equation for lightness determined by the RSM is shown in Table 3 .

3.6. Color. The parboiling process profoundly affects the color of the processed rice. $R^{2}$ and adjusted $R^{2}$ for the equation describing color were found to be 0.94 and 0.89 , respectively, and the lack of fit was also nonsignificant, indicating that the current quadratic model was found to be suitable to explain the relationship. Figures 6(a), 6(b), and 6(c) show the interaction effects of the soaking temperaturetime and steaming time combination on the color value. The color value ranged from 11.80 to 14.56 , with the darkest color rice obtained at the highest steaming time ( $18.41 \mathrm{~min})$, which can also be seen from Figures 6(b) and 6(c). The soaking temperature slightly affected the rice color, but steaming time greatly affected the rice color, as longer duration soaking and steaming led the rice bran pigments to penetrate into the endosperm $[13,37]$. The reaction of released sugar with an amino acid of grain during parboiling could lead to discoloration of rice [38]. The color finding in the current study revealed that greater severity of parboiling led to the development of dark colored rice during parboiling. The regression equation generated by the Design-Expert for color is presented in Table 3 . 


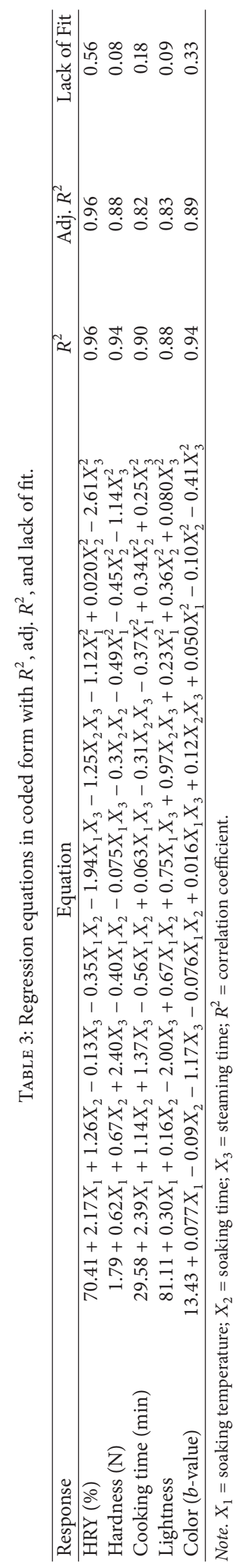



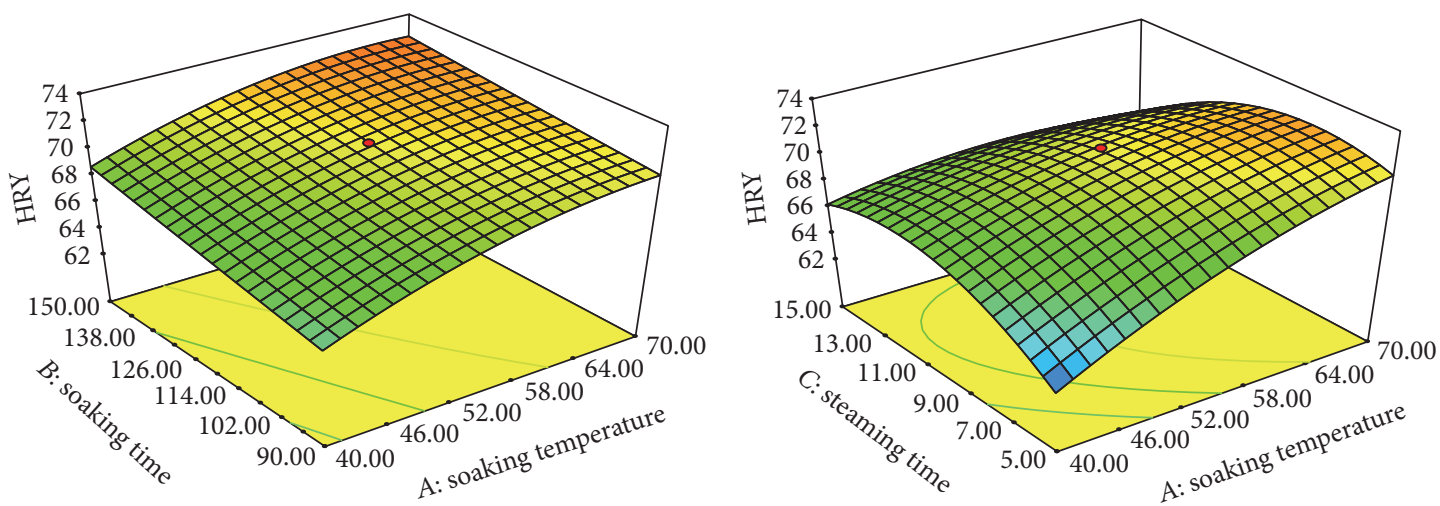

\author{
Design-Expert software \\ Factor coding: actual \\ HRY \\ - Design points above predicted value \\ - Design points below predicted value \\ $\prod_{60.82}^{73.88}$ \\ $X 1=A$ : soaking temperature \\ $X 2=B$ : soaking time \\ Actual factor \\ $C:$ steaming time $=10.00$
}
Design-Expert software
Factor coding: actual
HRY
- Design points above predicted value
- Design points below predicted value
\} 6 0 . 8 2
$X 1=A$ : soaking temperature
$X 2=C$ : steaming time
Actual factor
$B$ : soaking time $=120.00$

(a)

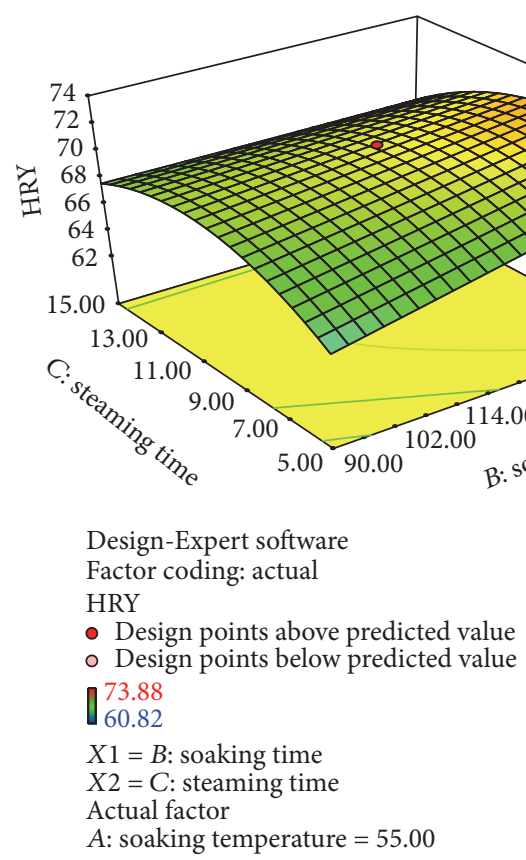

(c)

FIGURE 2: Effect of soaking temperature, soaking time, and steaming time on percentage HRY.

\section{Conclusion}

The RSM was used to jointly optimize the set of responses. The optimal values were obtained for responses by solving the regression equations of independent variables using DesignExpert software. In this study, the optimized combinations of soaking temperature, soaking time, and steaming time were determined primarily to improve HRY and other quality attributes. HRY is the most important rice quality characteristic. Therefore, in the Design-Expert software, HRY was maximized while other quality parameters were maintained within the appropriate ranges. Based on RSM data analysis, the predicted optimum soaking temperature, soaking time, and steaming time were $69.88^{\circ} \mathrm{C}, 150 \mathrm{~min}$, and $6.73 \mathrm{~min}$. Under these conditions, the predicted HRY is $73.43 \%$, hardness is $29.95 \mathrm{~N}$, cooking time is $32.14 \mathrm{~min}$, lightness is 83.03 , and 

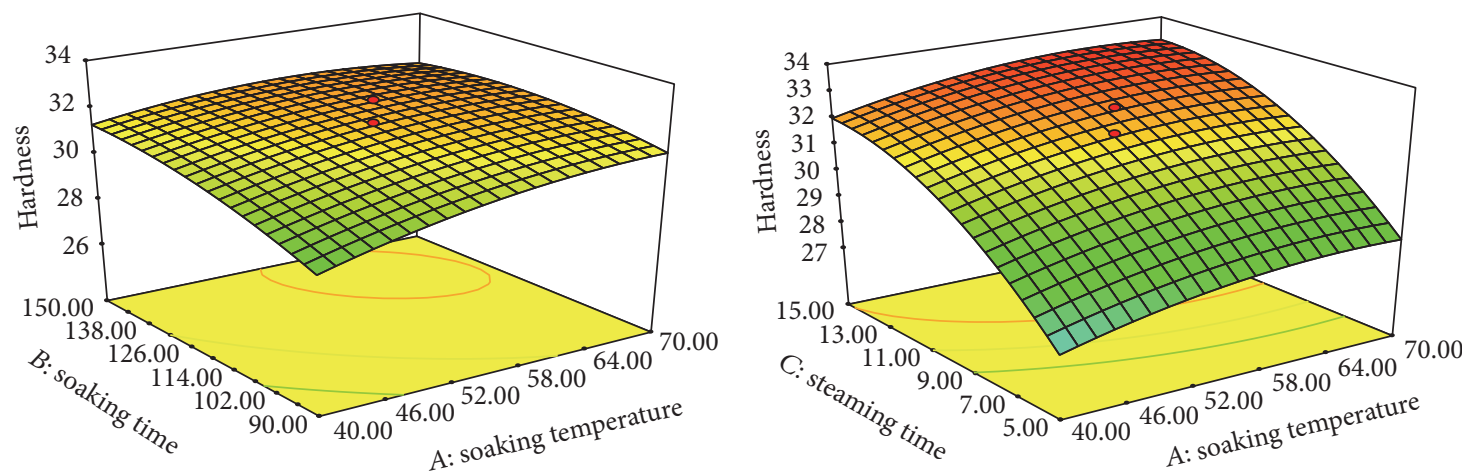

Design-Expert software

Factor coding: actual

Hardness

- Design points above predicted value

- Design points below predicted value

33.56

24.02

$X 1=A$ : soaking temperature

$X 2=B$ : soaking time

Actual factor

$C:$ steaming time $=10.00$

Design-Expert software

Factor coding: actual

Hardness

- Design points above predicted value

- Design points below predicted value

33.56

U24.02

$X 1=A$ : soaking temperature

$X 2=C$ : steaming time

Actual factor

$B$ : soaking time $=120.00$

(a)

(b)

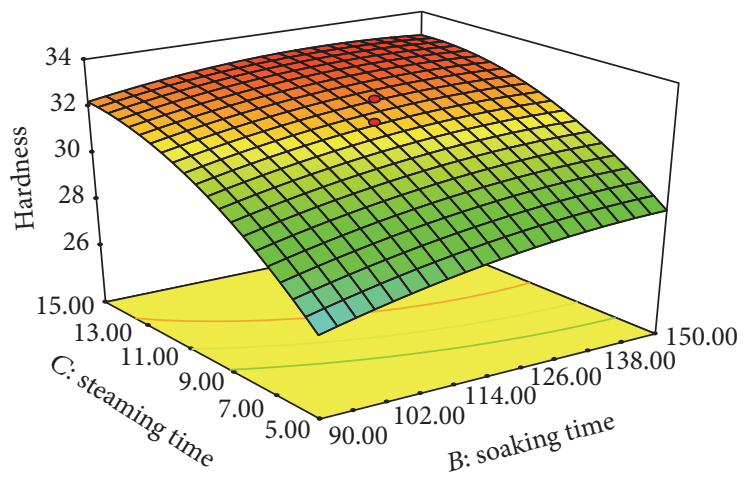

Design-Expert software
Factor coding: actual
Hardness
O Design points above predicted value
O Design points below predicted value
$\prod_{23.56}^{33.02}$
$X 1=B$ : soaking time
$X 2=C$ : steaming time
Actual factor
A: soaking temperature $=55.00$

(c)

FIGURE 3: Interactional effect of three variables on hardness of rice kernels.

color is 12.24 , with a composite desirability of 0.9658 . Variation in the factors studied here highly influenced the HRY and other quality traits. Increased soaking temperature and soaking time above the optimum condition resulted in lower HRY as explained in the earlier section. Similarly, increased steaming time affected color and lightness and increased hardness and cooking time due to the severe gelatinization of starch. The optimal condition maximizes HRY and maintains other quality properties within acceptable ranges.

The RSM combined with the CCD was successfully applied to the optimization of rice quality indicators (HRY, hardness, cooking time, lightness, and color) during the parboiling process. The $R^{2}$ values for all responses were greater than $80 \%$, and the lack of fit test was also observed 

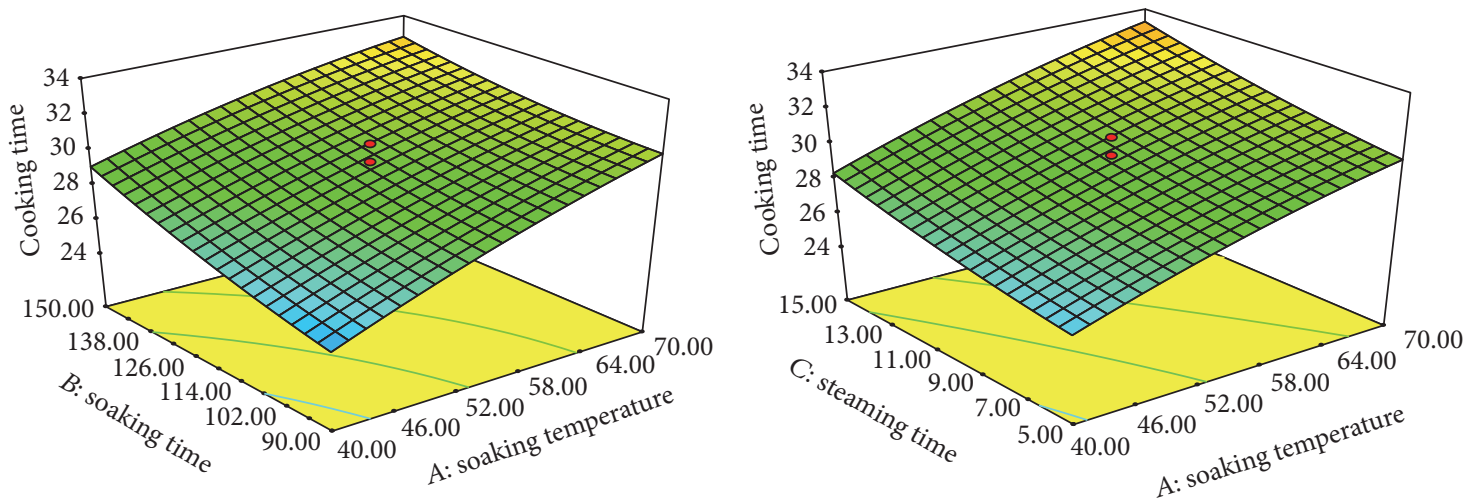

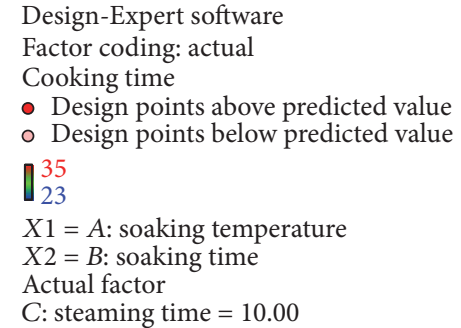

(a)
Design-Expert software
Factor coding: actual
Cooking time
- Design points above predicted value
- Design points below predicted value
$\prod_{23}^{35}$
$X 1=A$ : soaking temperature
$X 2=C$ : steaming time
Actual factor
$B$ : soaking time $=120.00$

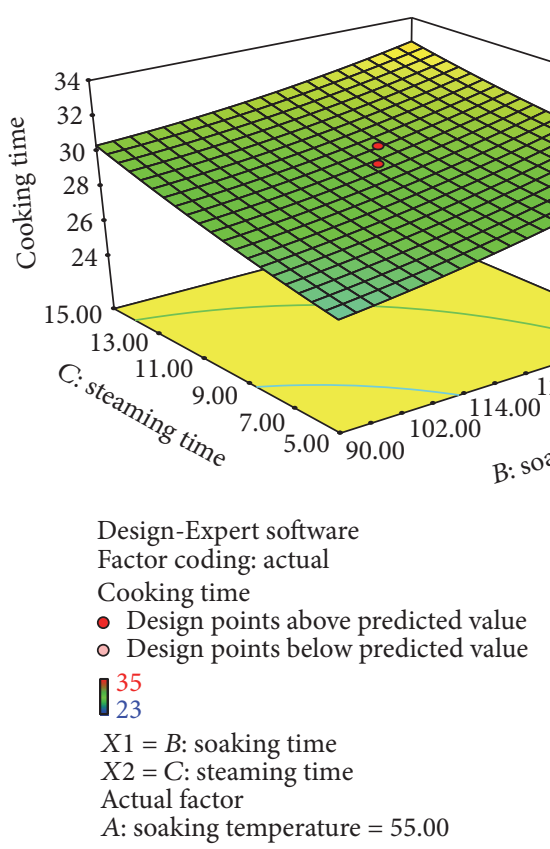

(b)

(c)

FIGURE 4: The cooking time affected by soaking temperature, soaking time, and steaming time.

to be nonsignificant for all response variables. Rice parboiled under the following conditions (soaking temperature $=69.88^{\circ} \mathrm{C}$, soaking time $=150 \mathrm{~min}$, and steaming time $=$ $6.73 \mathrm{~min}$ ) is predicted to exhibit optimal HRY and other quality indicators. The results showed that the RSM could be used to obtain the optimal HRY and other quality indicators of parboiled rice. The current experimental results could be used by the rice processing industry to significantly improve rice quality.

\section{Additional Points}

Practical Application. The primary purpose of parboiling process is to restore rice nutritional value for the quality point of view. The cost of parboiling process depends on a range of parboiling process indicators (soaking temperature, soaking time, and steaming time); if these variables are high then cost will be increased. Thus, there is a need to find optimal condition of these variables to decrease the process 

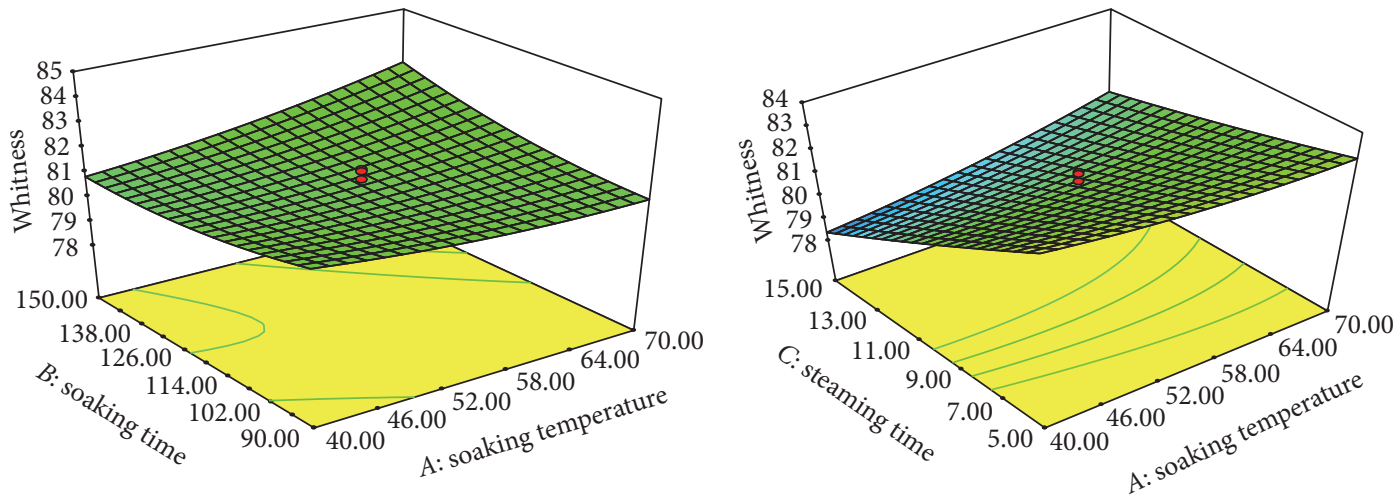

Design-Expert software

Factor coding: actual

Whitness

- Design points above predicted value

- Design points below predicted value

86.48

77.23

$X 1=A$ : soaking temperature

$X 2=B$ : soaking time

Actual factor

$C$ : steaming time $=10.00$

Design-Expert software

Factor coding: actual

Whitness

- Design points above predicted value

- Design points below predicted value

86.48

77.23

$X 1=A$ : soaking temperature

$X 2=C$ : steaming time

Actual factor

$B$ : soaking time $=120.00$

(a)

(b)

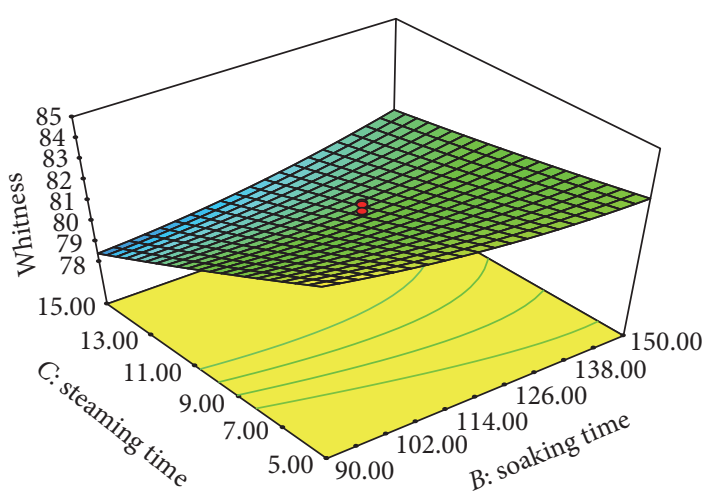

Design-Expert software

Factor coding: actual

Whitness

- Design points above predicted value

- Design points below predicted value

I 86.48

$X 1=B$ : soaking time

$X 2=C$ : steaming time

Actual factor

$A$ : soaking temperature $=55.00$

(c)

FIGURE 5: Effect of soaking temperature, soaking time, and steaming time on lightness.

cost and improve plant turnover for better rice quality. For this purpose, a mathematical model was used to predict the quality properties (HRY, hardness, cooking time, lightness, and color) by parboiling process indicators. The parboiling industry could use the findings of a current study to get the desired quality of parboiled rice. Therefore, optimization of parboiling process is economically essential for the rice industry. The manuscript will be helpful for researchers working particularly on commercializing the parboiled rice.

\section{Conflicts of Interest}

The authors declare that there are no conflicts of interest. 

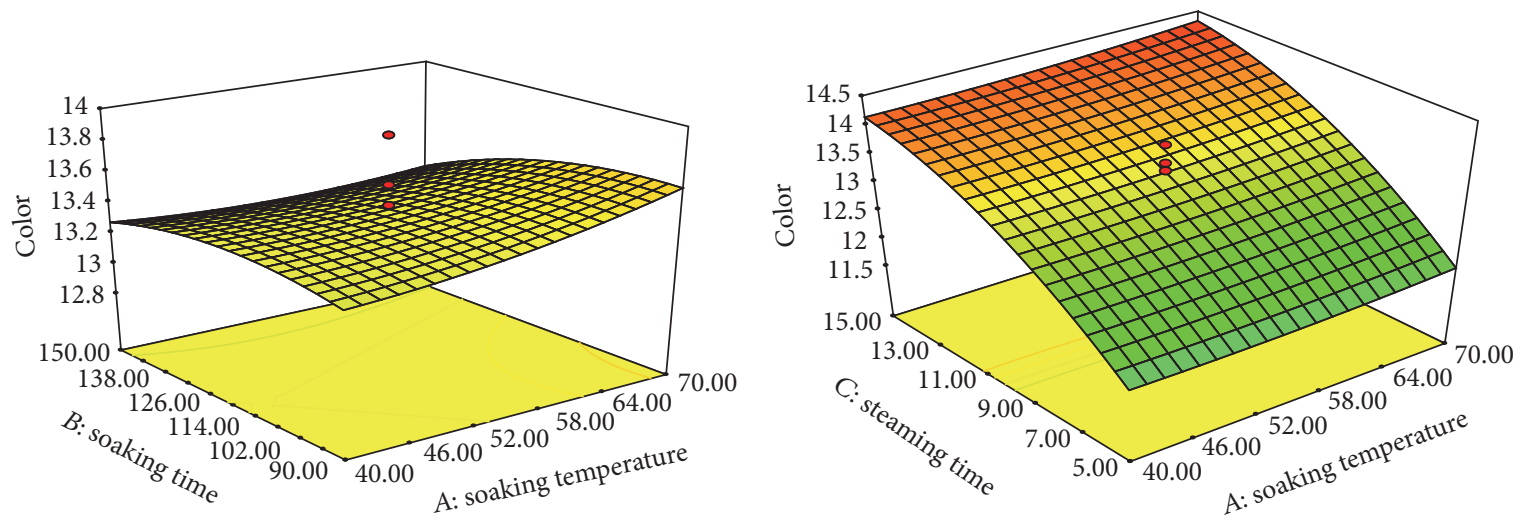

\author{
Design-Expert software \\ Factor coding: actual \\ Color \\ - Design points above predicted value \\ - Design points below predicted value \\ 14.56
10.03 \\ $X 1=A$ : soaking temperature \\ $X 2=B$ : soaking time \\ Actual factor \\ $C$ : steaming time $=10.00$
}

\author{
Design-Expert software \\ Factor coding: actual \\ Color \\ - Design points above predicted value \\ - Design points below predicted value \\ 14.56 \\ 10.03 \\ $X 1=A$ : soaking temperature \\ $X 2=C$ : steaming time \\ Actual factor \\ $B$ : soaking time $=120.00$
}

(a)
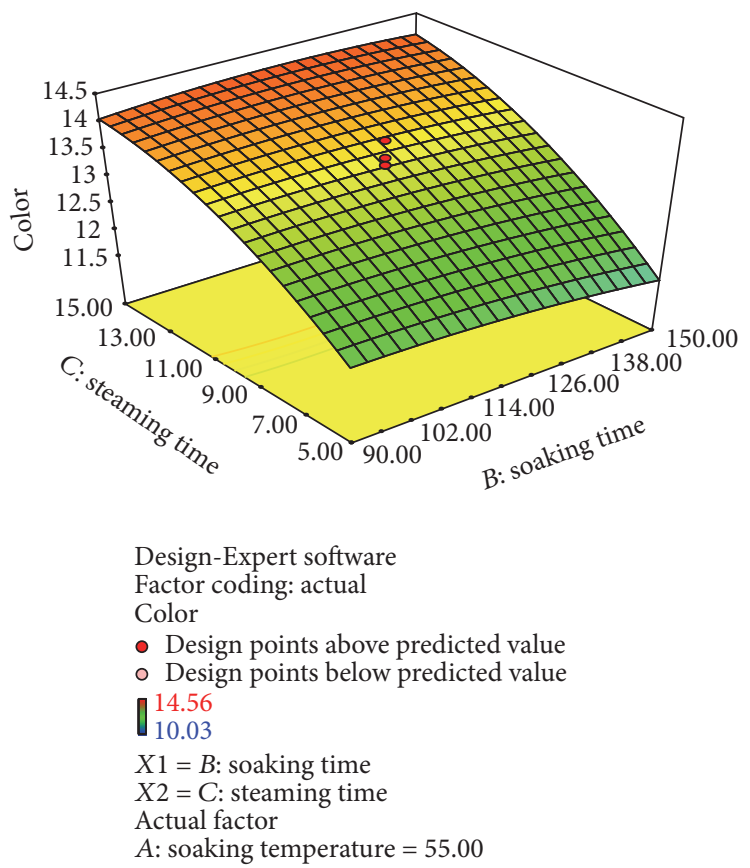

(c)

FIGURE 6: Effect of soaking temperature, soaking time, and steaming time on color (b-value).

\section{Acknowledgments}

All experimentation and study were conducted with the help and funding of College of Engineering, Nanjing Agriculture University, China. The first author thankfully acknowledges China Scholarship Council (CSC) for providing all kinds of possible facilities during the study in China.

\section{References}

[1] G. Elbert, M. P. Tolaba, and C. Suárez, "Effects of drying conditions on head rice yield and browning index of parboiled rice," Journal of Food Engineering, vol. 47, no. 1, pp. 37-41, 2001.

[2] J. Buggenhout, K. Brijs, J. Van Oevelen, and J. A. Delcour, "Milling breakage susceptibility and mechanical properties of 
parboiled brown rice kernels," LWT-Food Science and Technology, vol. 59, no. 1, pp. 369-375, 2014.

[3] K. Itoh, S. Kawamura, and Y. Ikeuchi, "Processing and Milling of Parboiled Rice," Journal of the Faculty of Agriculture, Hokkaido University, vol. 62, no. 3, pp. 312-324, 1985.

[4] K. R. Unnikrishnan and K. R. Bhattacharya, "Properties of pressure parboiled rice as affected by variety," Cereal Chemistry, vol. 64, no. 4, pp. 321-323, 1987.

[5] M. Walter, E. Marchesan, P. F. S. Massoni, L. P. da Silva, G. M. S. Sartori, and R. B. Ferreira, "Antioxidant properties of rice grains with light brown, red and black pericarp colors and the effect of processing," Food Research International, vol. 50, no. 2, pp. 698703, 2013.

[6] K. R. Bhattacharya and P. V. S. Rao, "Effect of processing conditions on quality of parboiled rice," Journal of Agricultural and Food Chemistry, vol. 14, no. 5, pp. 476-479, 1966.

[7] F. Gariboldi, "Rice parboiling," in FAO Agricultural Development, vol. 97, pp. 1-97, Room Italy: Food and Agriculture Organization of the United Nations, 1974.

[8] K. Arai, S. N. R. Rao, and H. S. R. Desikachar, "Studies of the effect of parboiling on Japonica and Indica rice," Japanese Journal of Tropical Agriculture, vol. 19, no. 1, pp. 7-14, 1975.

[9] J. A. Delcour and R. C. Hoseney, "Rice and oat processing," in Principles of Cereal Science and Technology, pp. 149-160, AACC International Incorporated, St. Paul, Minn, USA.

[10] M. Bello, R. Baeza, and M. P. Tolaba, "Quality characteristics of milled and cooked rice affected by hydrothermal treatment," Journal of Food Engineering, vol. 72, no. 2, pp. 124-133, 2006.

[11] M. R. Islam, N. Shimizu, and T. Kimura, "Energy requirement in parboiling and its relationship to some important quality indicators," Journal of Food Engineering, vol. 63, no. 4, pp. 433439, 2004.

[12] K. Sareepuang, S. Siriamornpun, L. Wiset, and N. Meeso, "Effect of soaking temperature on physical, chemical and cooking properties of parboiled fragrant rice," World Journal of Agricultural Sciences, vol. 4, pp. 409-415, 2008.

[13] M. A. K. Miah, A. Haque, M. P. Douglass, and B. Clarke, "Parboiling of rice. Part II: effect of hot soaking time on the degree of starch gelatinization," International Journal of Food Science \& Technology, vol. 37, no. 5, pp. 539-545, 2002.

[14] E. Taghinezhad, M. H. Khoshtaghaza, S. Minaei, and A. Latifi, "Effect of soaking temperature and steaming time on the quality of parboiled Iranian paddy rice," International Journal of Food Engineering, vol. 11, no. 4, pp. 547-556, 2015.

[15] S. Sharma, A. Malik, and S. Satya, "Application of response surface methodology (RSM) for optimization of nutrient supplementation for Cr (VI) removal by Aspergillus lentulus AML05," Journal of Hazardous Materials, vol. 164, no. 2-3, pp. 1198-1204, 2009.

[16] D. Ghosh and P. C. Hallenbeck, "Response surface methodology for process parameter optimization of hydrogen yield by the metabolically engineered strain Escherichia coli DJT135," Bioresource Technology, vol. 101, no. 6, pp. 1820-1825, 2010.

[17] E. Taghinezhad and T. Brenner, "Mathematical modeling of starch gelatinization and some quality properties of parboiled rice based on parboiling indicators using RSM," Journal of Food Process Engineering, vol. 40, no. 3, Article ID e12483, 2017.

[18] N. Danbaba, I. Nkama, M. H. Badau et al., "Optimization of rice parboiling process for optimum head rice yield: a response surface methodology (RSM) approach," International Journal of Agriculture and Forestry, vol. 4, no. 3, pp. 154-165, 2014.
[19] M. O. Bello, R. J. Aguerre, M. P. Tolaba, and C. Suárez, "Effect of hydrothermal conditions on translucence of milled rice," in Color in Food: Technological and Pyschophysical Aspects, pp. 6369, Taylor Francis, 2012.

[20] F. E. Cherati, S. Kamyab, M. Shekofteh, and R. Derikvand, "Analysis and study of parboiling method and the following impact on waste reduction and operation increase of rice in paddy conversion phase," Research Journal of Applied Sciences, Engineering \& Technology, vol. 4, no. 16, pp. 2649-2652, 2012.

[21] M. Fofana, J. Wanvoeke, J. Manful et al., "Effect of improved parboiling methods on the physical and cooked grain characteristics of rice varieties in Benin," International Food Research Journal, vol. 18, no. 2, pp. 715-721, 2011.

[22] E. Taghinezhad, M. H. Khoshtaghaza, S. Minaei, T. Suzuki, and T. Brenner, "Relationship between degree of starch gelatinization and quality attributes of parboiled rice during steaming," Rice Science, vol. 23, no. 6, pp. 339-344, 2016.

[23] A. Latifi and M. R. Alizadeh, "Effect of parboiling on qualities and milling of Iranian rice," Journal of Agricultural and Engineering Research, vol. 15, no. 1, pp. 77-88, 2014.

[24] B. O. Juliano, "An international survey of methods used for evaluation of cooking and eating qualities of milled rice," in Proceedings of the International Rice Research Institute, vol. 77, pp. 142-153, Los Banos Laguna, Manila, Philippines, 1982.

[25] N. Singh, L. Kaur, N. Singh Sodhi, and K. Singh Sekhon, "Physicochemical, cooking and textural properties of milled rice from different Indian rice cultivars," Food Chemistry, vol. 89, no. 2, pp. 253-259, 2005.

[26] L. Lamberts, E. De Bie, G. E. Vandeputte et al., "Effect of milling on colour and nutritional properties of rice," Food Chemistry, vol. 100, no. 4, pp. 1496-1503, 2007.

[27] A. I. Khuri and J. A. Cornell, Response Surfaces: Designs and Analyses, Statistics: A Series of Textbooks and Monographs, Marcel Dekker, New York, NY, USA, 2nd edition, 1996.

[28] A. I. Khuri and J. A. Cornell, Response Surfaces: Designs and Analyses, Marcel Dekker, New York, NY, USA, 1987.

[29] E. Aghaie, M. Pazouki, M. R. Hosseini, M. Ranjbar, and F. Ghavipanjeh, "Response surface methodology (RSM) analysis of organic acid production for Kaolin beneficiation by Aspergillus niger," Chemical Engineering Journal, vol. 147, no. 2-3, pp. 245-251, 2009.

[30] A. J. Ayamdoo, B. Demuyakor, W. Dogbe, R. Owusu, and M. A. Ofosu, "Effect of varying parboiling conditions on physical qualities of Jasmine 85 and Nerica 14 rice varieties," American Journal of Food Technology, vol. 8, no. 1, pp. 31-42, 2013.

[31] W. E. Marshall, J. I. Wadsworth, L. R. Verma, and L. Velupillai, "Determination the degree of gelatinization in parboiled rice: comparison of a subjective and an objective method," Cereal Chemistry, vol. 70, no. 2, pp. 226-230, 1993.

[32] R. Islam, N. Shimizu, and T. Kimura, "Quality evaluation of parboiled rice with physical properties," Food Science and Technology Research, vol. 7, no. 1, pp. 57-63, 2001.

[33] A. Nasirahmadi, M. H. Abbaspour-Fard, B. Emadi, and N. B. Khazaei, "Modelling and analysis of compressive strength properties of parboiled paddy and milled rice," International Agrophysics, vol. 28, no. 1, pp. 73-83, 2014.

[34] S. M. H. Saif, D. A. Suter, and Y. Lan, "Effects of processing conditions and environmental exposure on the tensile properties of parboiled rice," Biosystems Engineering, vol. 89, no. 3, pp. 321330, 2004. 
[35] M. R. Islam, P. Roy, N. Shimizu, and T. Kimura, "Effect of processing conditions on physical properties of parboiled rice," Food Science and Technology Research, vol. 8, no. 2, pp. 106-112, 2002.

[36] S. Bhattacharya, "Kinetics on colour changes in rice due to parboiling," Journal of Food Engineering, vol. 29, no. 1, pp. 99106, 1996.

[37] L. Lamberts, E. De Bie, V. Derycke, W. S. Veraverbeke, W. De Man, and J. A. Delcour, "Effect of processing conditions on color change of brown and milled parboiled rice," Cereal Chemistry, vol. 83, no. 1, pp. 80-85, 2006.

[38] L. Lamberts, K. Brijs, R. Mohamed, N. Verhelst, and J. A. Delcour, "Impact of browning reactions and bran pigments on color of parboiled rice," Journal of Agricultural and Food Chemistry, vol. 54, no. 26, pp. 9924-9929, 2006. 

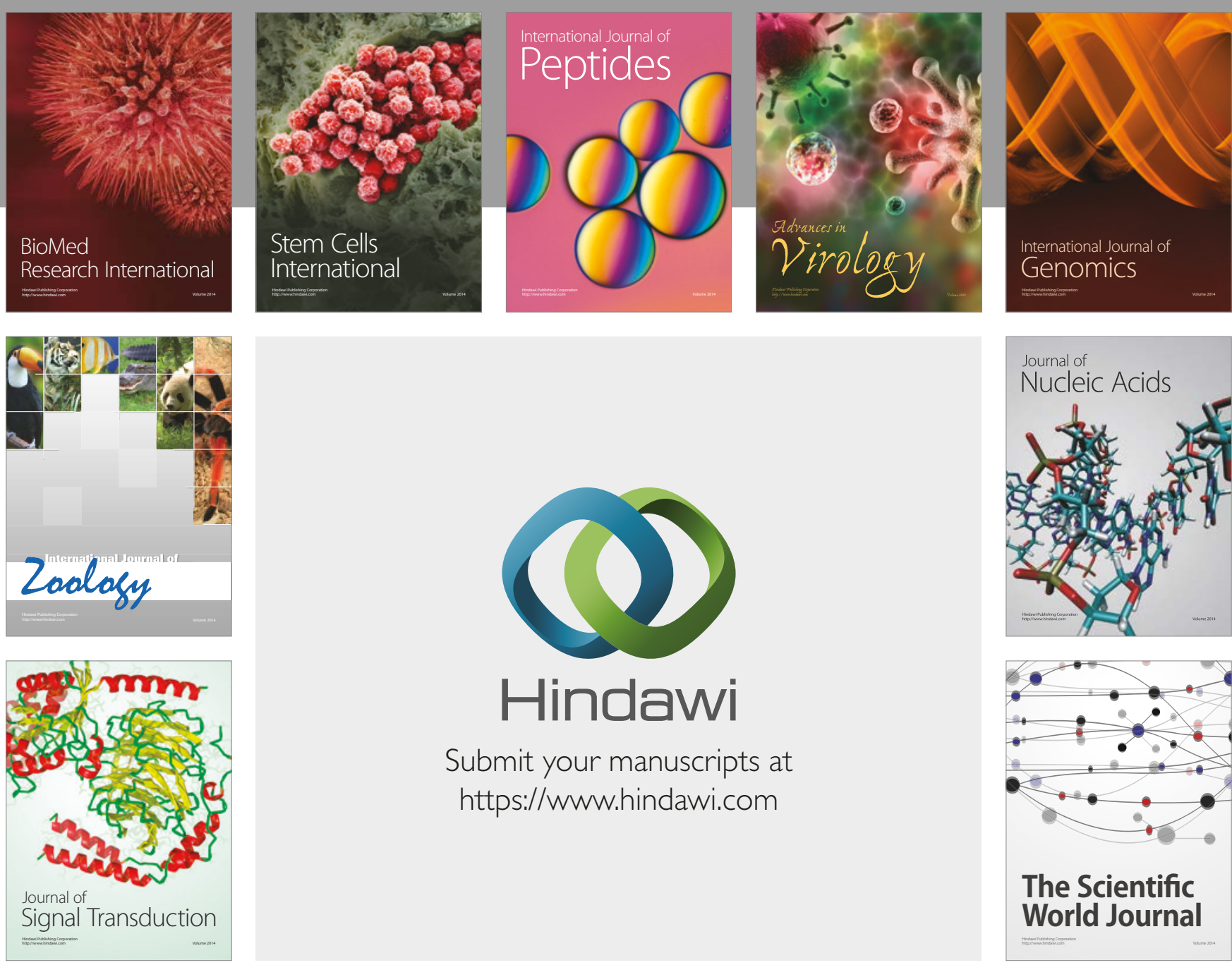

Submit your manuscripts at

https://www.hindawi.com
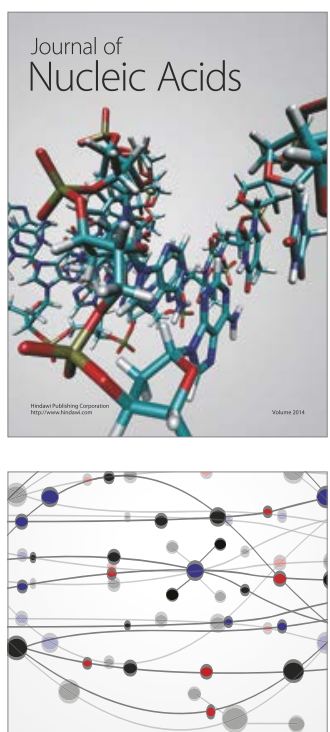

The Scientific World Journal

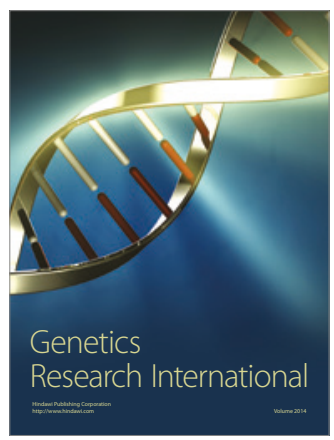

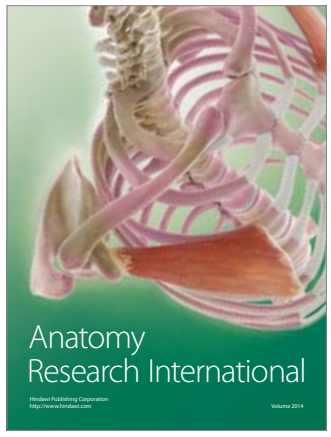

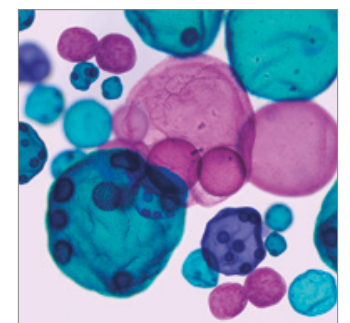

International Journal of Microbiology
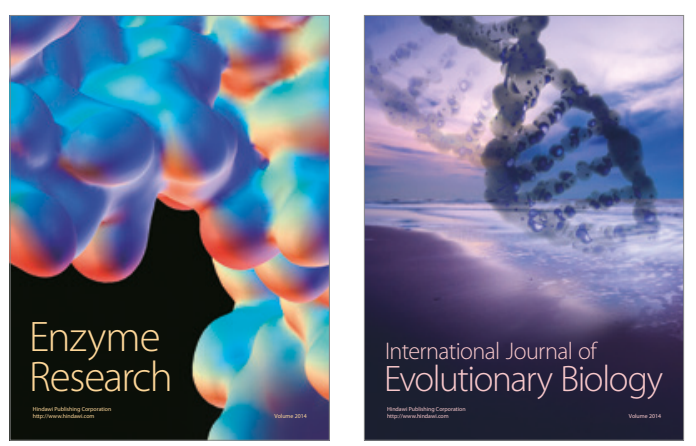
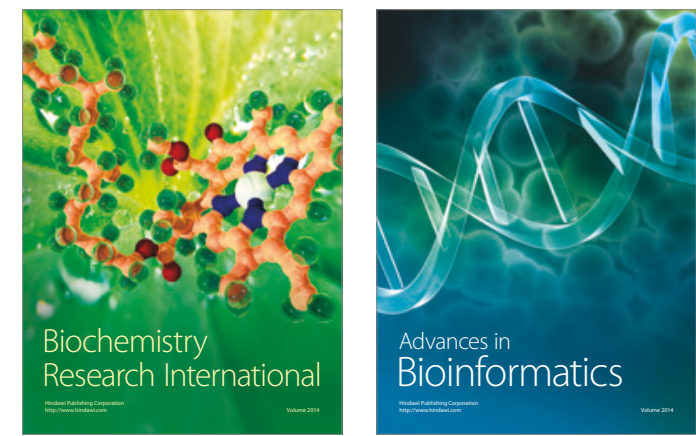

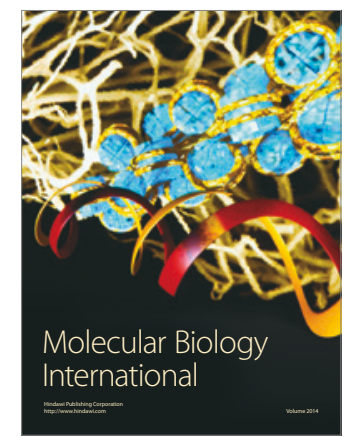

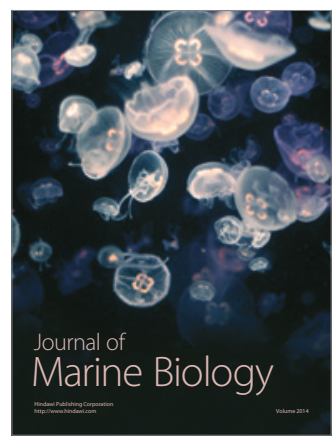

